\title{
Large cell neuroendocrine carcinoma of the lung that responded to nivolumab: A case report
}

\author{
MICHIKO TAKIMOTO SATO ${ }^{1}$, YASUYUKI IKEZAWA ${ }^{1}$, MINEYOSHI SATO ${ }^{1}$, \\ AKIRA SUZUKI $^{2,3}$ and YASUTAKA KAWAI ${ }^{1}$ \\ Departments of ${ }^{1}$ Respiratory Medicine and ${ }^{2}$ Pathology, Oji General Hospital, Tomakomai, Hokkaido 0538506; \\ ${ }^{3}$ Department of Pathology, KKR Sapporo Medical Center, Sapporo, Hokkaido 0620931, Japan
}

Received January 19, 2019; Accepted April 28, 2020

DOI: $10.3892 / \mathrm{mco} .2020 .2045$

\begin{abstract}
Pulmonary large cell neuroendocrine carcinoma (LCNEC) is a rare type of lung cancer, accounting for $3 \%$ of all lung cancers. The prognosis is poor and the standard therapy has not been well established. Herein, we report a case of advanced LCNEC of the lung that responded to nivolumab. The patient was a 62-year old man with stage IVB LCNEC of the lung. The disease progressed following the administration of second-line chemotherapy, and he was treated with nivolumab $3 \mathrm{mg} / \mathrm{kg}$ as the third-line treatment. Although treatment was ceased after two cycles due to interstitial pneumonia, the disease remained stable for approximately six months under observation. There was no other adverse event related to nivolumab. Following patient mortality from tumor progression, PD-L1 expression was observed to be negative (tumor proportion score $<1 \%$ ) by a re-examination of the primary biopsy specimen. The case herein suggests that nivolumab may be a possible treatment option for LCNEC.
\end{abstract}

\section{Introduction}

The programmed death-1 (PD-1) receptor expressed on T-cells is engaged by tumor-expressed PD-ligand (PD-L) 1 and PD-L2 inhibiting T-cell activation and promoting tumor immune escape. Immune checkpoint inhibitors block the immune checkpoint molecules expressed on cancer cells, thereby blocking the inhibitory signals from the ligand and prolonging the activation of T-cells. Thus, T-cells are induced to attack the cancer cells (1). Nivolumab, a fully human $\mathrm{IgG}_{4}$ PD-1 immune checkpoint inhibitor antibody, emerged as a promising treatment option for advanced non-small cell lung carcinoma

Correspondence to: Dr Yasuyuki Ikezawa, Department of Respiratory Medicine, Oji General Hospital, 3-4-8 Wakakusa-cho, Tomakomai, Hokkaido 0538506, Japan

E-mail: ikezawa0210yasuyuki@gmail.com

Key words: large cell neuroendocrine carcinoma, nivolumab, immune checkpoint inhibitor, programmed death-1 (PD-1), PD-1 antibody
(NSCLC). In two phase III trials, nivolumab demonstrated superior overall survival (OS) compared to docetaxel among pre-treated patients with advanced NSCLC $(2,3)$. Furthermore, Gettinger et al reported that first-line nivolumab monotherapy demonstrated a tolerable safety profile and durable responses in advanced NSCLC (4).

Large cell neuroendocrine carcinoma (LCNEC) is a rare subset of lung cancer, accounting for 3\% of all lung cancer (5). In the current 2015 World Health Organization (WHO) Classification of Tumors of the Lung, Pleura, Thymus and Heart, LCNECs are classified as neuroendocrine neoplasms with small cell lung carcinoma (SCLC), typical carcinoids, and atypical carcinoids (6). Since there are limited published data regarding the natural history, clinical course, and treatment of patients with advanced LCNEC, the optimal systemic treatment has not been adequately established.

Although the effectiveness of PD-1 antibody for NSCLC has been reported, the effectiveness of PD-1 antibody for LCNEC is unclear. We recently encountered a case of stage IVB LCNEC of the lung that responded to nivolumab as third-line treatment.

\section{Case report}

A 62-year-old man presented with weakness of the lower extremities and numbness of the right index finger. He had a smoking history of 40 cigarettes per day for 40 years and a history of hypertension and gastroesophageal reflux disease. He visited a hospital, and the chest X-ray showed an abnormal shadow on the right lung. Chest computed tomography (CT) revealed a mass in the right upper lobe, metastases in the mediastinal lymph nodes, and bone metastasis at the sixth cervical vertebra (Fig. 1). He was referred to our hospital and diagnosed with LCNEC of the lung (cT1bN2M1b, c-Stage IVB) by transbronchial needle aspiration. Immunohistochemical staining showed the tumor cells were positive for chromogranin A, CD56, and synaptophysin (Fig. 2A-E). At diagnosis, the serum NSE slightly was elevated $(15.8 \mathrm{ng} / \mathrm{ml})$ and ProGRP was within a normal range. We performed radiotherapy for the bone metastasis at the cervical vertebra immediately, followed by first-line chemotherapy with irinotecan $60 \mathrm{mg} / \mathrm{m}^{2}$ and carboplatin $(\mathrm{AUC}=5)$. Post-treatment $\mathrm{CT}$ showed stable disease. After a disease-free interval of five months, CT 

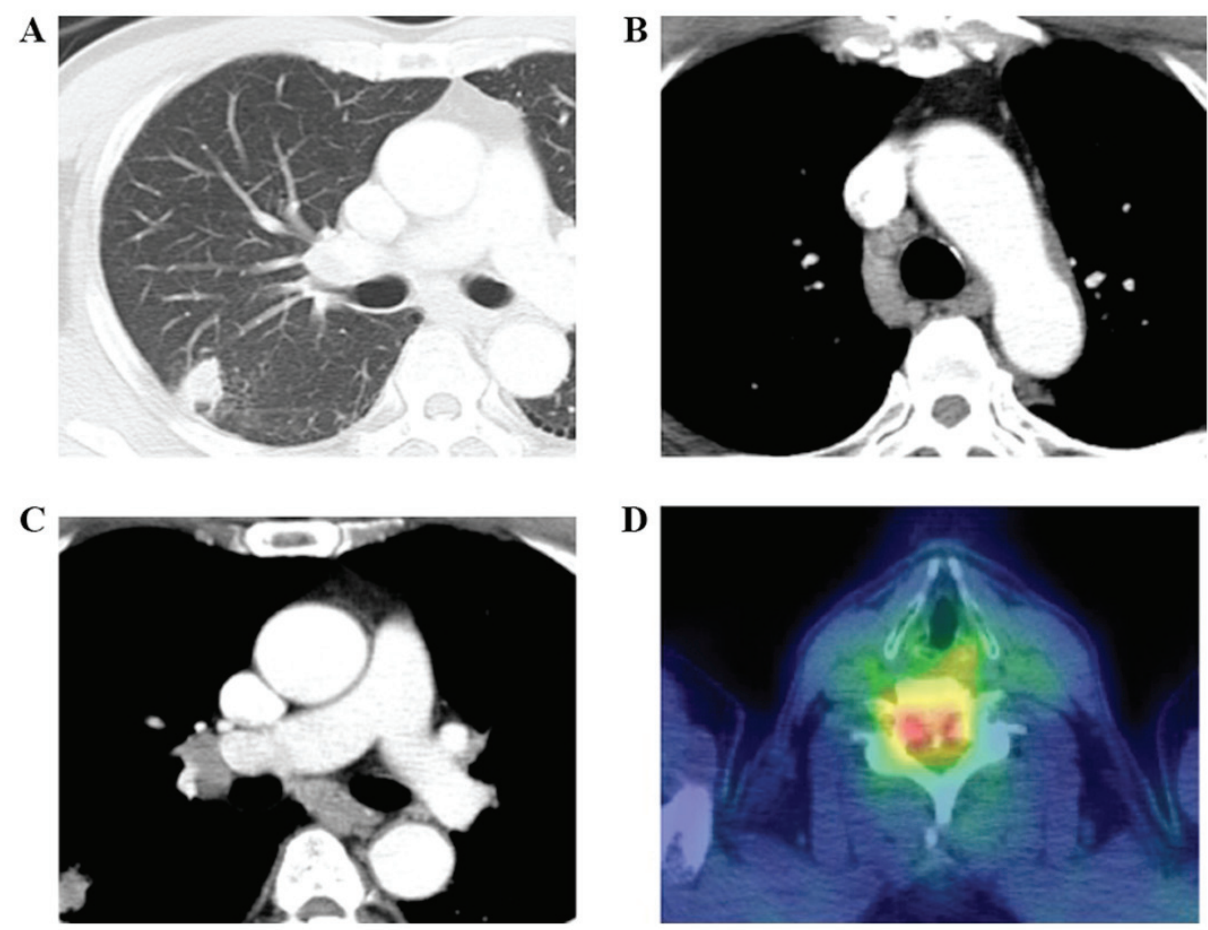

Figure 1. Chest computed tomography (CT) on admission revealed (A) a mass in the right upper lobe and (B and C) several metastases in the mediastinal lymph nodes. (D) Positron emission tomography-CT showed bone metastases at the cervical vertebra.

revealed multiple new metastases in the abdominal lymph nodes, liver, and bones. We administered etoposide $80 \mathrm{mg} / \mathrm{m}^{2}$ and cisplatin $60 \mathrm{mg} / \mathrm{m}^{2}$ as second-line chemotherapy; however, lymph node metastases progressed rapidly and serum NSE level was elevated to $22.1 \mathrm{ng} / \mathrm{ml}$.

Next, he was treated with nivolumab $3 \mathrm{mg} / \mathrm{kg}$ as third-line chemotherapy. We found mild hyperthyroidism through a serological testing and initiated oral replacement therapy. After two cycles of nivolumab, the primary lesion and most of the lymph node metastases shrank; however, one liver metastasis and one mediastinal lymph node enlarged slightly. All these changes were within the range for stable disease (Fig. 3). Concurrently, although the patient didn't present any symptom such as shortness of breath or dry cough, interstitial pneumonia developed. We stopped nivolumab and administered $20 \mathrm{mg}$ per day of oral predonisolone. After 8 days, the chest X-ray showed improvement of pneumonia and we stopped predonisolone. Interstitial pneumonia hadn't exaggerated again although it had remained until the end. Hyperthyroidism had also remained stable, and there was no other adverse event related to nivolumab. Thereafter, the disease remained stable for approximately six months under observation (Fig. 3) and NSE gradually improved to $15.7 \mathrm{ng} / \mathrm{ml}$.

Seven months after starting nivolumab, all liver metastases enlarged and multiple brain metastases developed. We found NSE was elevated to $26.5 \mathrm{ng} / \mathrm{ml}$, and it continued to be elevated until he died (maximum was $87.8 \mathrm{ng} / \mathrm{ml}$ ) (Fig. 4). $\mathrm{He}$ received whole brain radiotherapy and one cycle of fourth-line chemotherapy with amrubicin $30 \mathrm{mg} / \mathrm{m}^{2}$. He died from tumor progression soon thereafter. After his death, we made a restudy of the primary biopsy specimen by immunohistochemistry and found that PD-L1 expression was negative (tumor proportion score $<1 \%$ ) (Fig. 2F).

\section{Discussion}

We report a case of stage IVB LCNEC of the lung without PD-L1 expression that responded to nivolumab as third-line treatment. The recent update of the WHO Classification of Tumors of the Lung, Pleura, Thymus and Heart provides diagnostic criteria for neuroendocrine carcinomas based on the histopathologic characteristics such as cell size, cell morphologic features, mitotic index, architectural growth patterns, and the presence of necrosis. Tumors with these neuroendocrine morphologies are divided into four subtypes, high-grade malignancies together with SCLC or LCNEC, low-grade typical carcinoids, and intermediate grade atypical carcinoids, primarily according to the number of mitoses, the presence or absence of necrosis, and the detection of immunohistochemical markers such as chromogranin A, synaptophysin, and CD56. Furthermore, LCNEC can harbor components of adenocarcinoma, squamous cell carcinoma, giant cell carcinoma, or spindle cell carcinoma. When SCLC is combined with LCNEC, the tumor is both clinically and morphologically diagnosed as an SCLC.

The most appropriate treatment strategy for advanced LCNEC has not been established, because of its rarity and difficulty of diagnosis. Some studies examining the first- and second-line treatment of LCNEChave been performed, and most showed that chemotherapies for SCLC were potentially more effective than those for NSCLC (7-10). Niho et al reported the results of a phase II trial of cisplatin and irinotecan as first-line therapy. Forty-four patients were enrolled. The response rate was $54.5 \%$, and the median PFS/OS was 5.9/15.1 months, respectively (7). Le Treut et al reported the results of a phase II trial of cisplatin and etoposide as first-line therapy. Forty-two patients were enrolled, and the median PFS/OS was 5.2/7.7 months, respectively (8). Kasahara et al reported the 
A

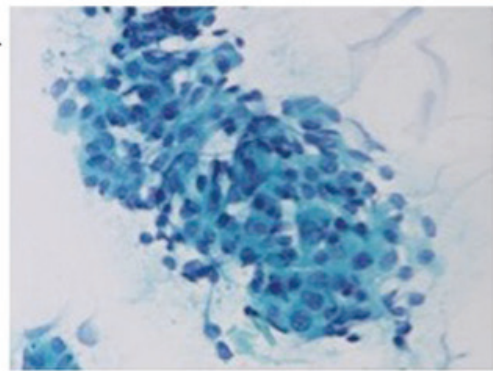

D

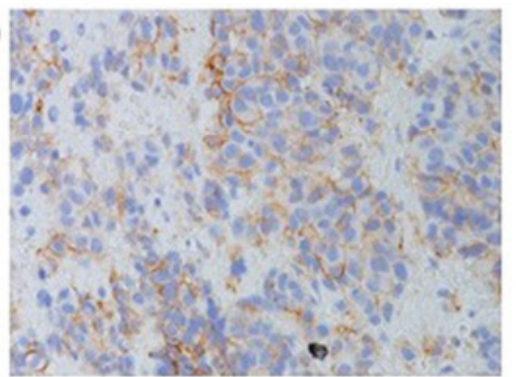

B

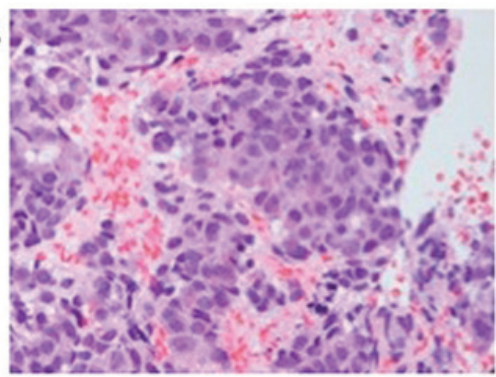

$\mathbf{E}$

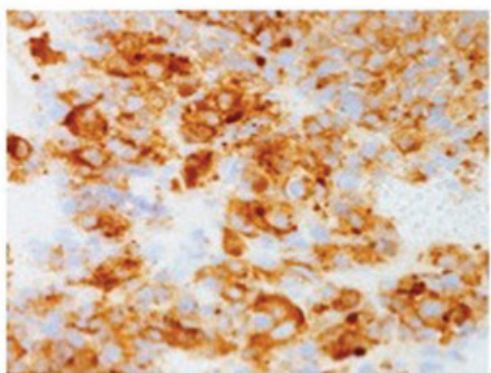

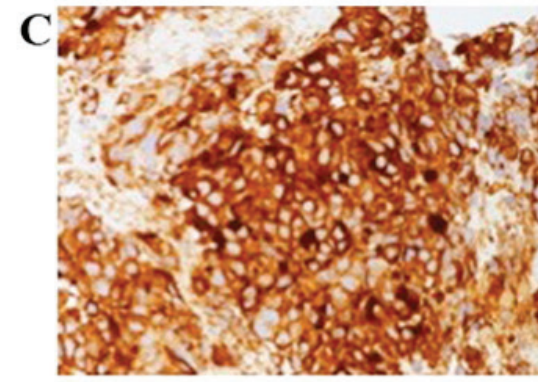

$\mathbf{F}$

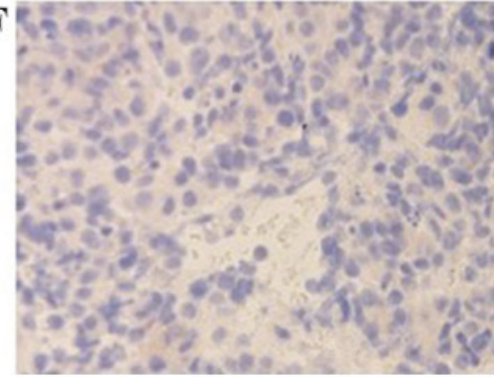

Figure 2. Microscopic findings (x40 magnification). (A) Cytological findings revealed tumor cells with moderate to abundant cytoplasm and enlarged hyperchromatic nuclei in several clusters (Papanicolaou stain). (B) Tumor cells had variably abundant cytoplasm and large nuclei. Nucleoli were frequent, and some tumor cells had prominent nucleoli (hematoxylin \& eosin stain). Immunohistochemical staining showed the tumor cells were positive for (C) chromogranin A, (D) CD56, and (E) synaptophysin. (F) PD-L1 expression was negative (tumor proportion score $<1 \%$ ).

A
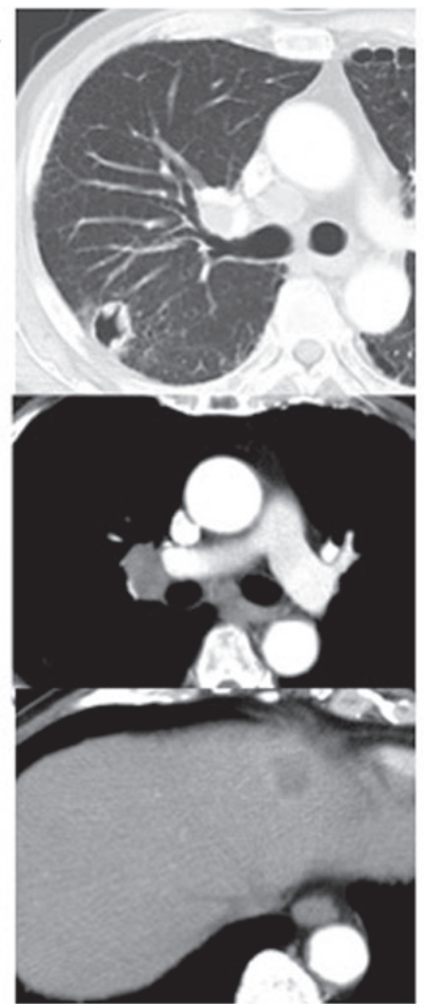

Before nivolumab
B
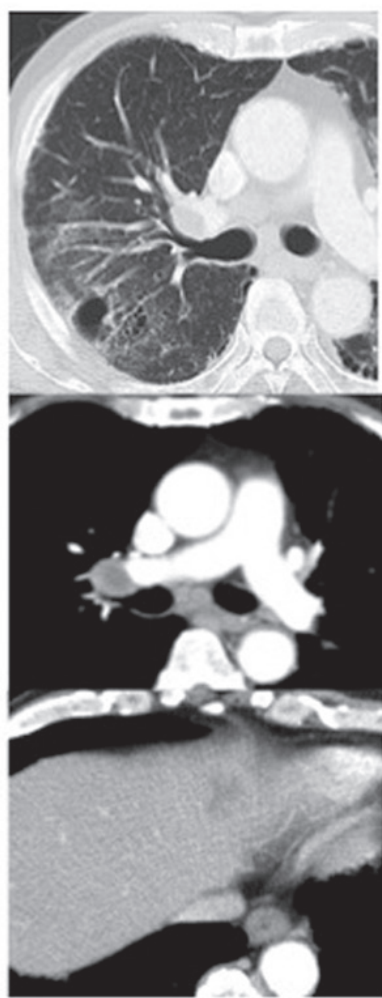

After two cycles
C
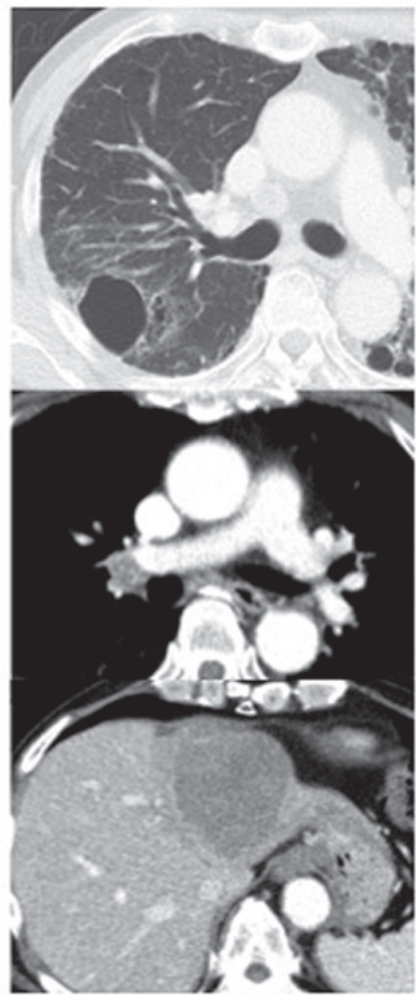

At the time of progress

Figure 3. CT findings. (A) Before starting nivolumab. (B) After two cycles of nivolumab, the primary lesion and most of the metastases in the lymph nodes and the liver had shrunk; however, some lesions were slightly enlarged. (C) After six months under observation, liver metastases had enlarged, and multiple brain metastases appeared.

results of a phase II trial of amrubicin as second-line therapy. Eighteen patients were enrolled; the response rate was $27.7 \%$, and the median PFS/OS was 3.1/5.1 months, respectively (9).
These studies showed that the outcomes of advanced LCNEC treated with certain regimens for SCLC were poorer than those of patients with advanced SCLC. In contrast, several 


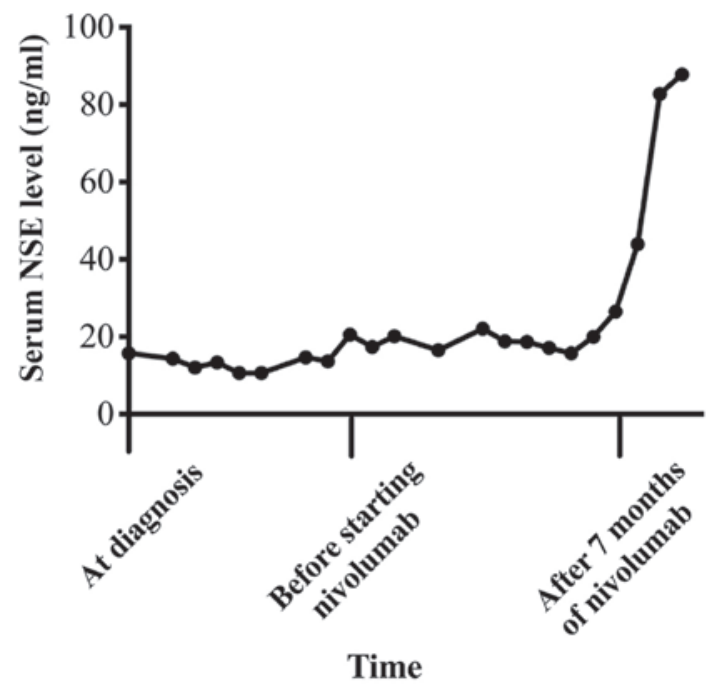

Figure 4. Serum NSE levels. The serum NSE level was slightly elevated at diagnosis and decreased after starting nivolumab. And it elevated again when the disease progressed.

cohort studies have evaluated NSCLC regimens for LCNEC; however, these studies were retrospective, and the sample sizes were small (10). Taken together, new treatment options for this rare malignancy are essential.

Some studies reported PD-L1 expression in $15.2-57.5 \%$ of NSCLCs, and there was an association between higher PD-L1 expression and greater clinical benefit of PD-1 inhibitors such as nivolumab or pembrolizumab, another immune checkpoint inhibitor antibody, for patients with NSCLCs $(2,11,12)$. A recent study showed that the frequency of PD-L1 expression was $10.4 \%$ in LCNECs in surgically resected specimens, and there was a tendency towards longer OS and disease-free survival in patients with positive PD-L1 expression than in those with negative PD-L1 expression (13). However, there have been few reports of LCNEC that responded to nivolumab or pembrolizumab $(14,15)$ and the effectiveness of PD-L1 antibodies for LCNEC is unclear. In our case, the primary lesion and most of the lymph node metastases responded to nivolumab. In addition, the disease remained stable regardless of poor PD-L1 expression, and only one liver metastasis developed. PD-L1 protein expression has been reported to be heterogeneous $(16,17)$ and we speculated that this heterogeneity might partly explain the mixed responses in different tumor sites or organs. Futhermore, it was reported that high tumor mutation burden (TMB) may be predictive of response to immunotherapy $(14,18)$ or patient outcomes were significantly better when immune-related adverse events occurred in a population of patients with advanced NSCLC treated with immune checkpoint inhibitors (19). In our case, there may be an association between TMB and/or interstitial pneumonia incidence and efficacy of nivolumab. Further cases are required to investigate the various predictors of better outcomes to immune check point inhibitors of this rare malignancy.

In conclusion, disease remained stable for seven months after only two cycles of nivolumab. Our case suggests that immune checkpoint inhibitors can be an effective treatment option for patients with advanced LCNEC.

Nivolumab is a possible treatment option for LCNEC.

\section{Acknowledgements}

Not applicable.

\section{Funding}

No funding was received.

\section{Availability of data and materials}

The datasets used in this manuscript are available from the corresponding author on reasonable request.

\section{Authors' contributions}

MTS took part in the medical treatment for the patient and wrote the manuscript. YI took part in the treatment and supervised writing the manuscript. MS took part in the treatment and supervised writing in English. YK played a major role in the treatment. AS contributed to pathological diagnosis. All authors read and approved the final manuscript.

\section{Ethics approval and consent to participate}

The Independent Ethics Committee of Oji General Hospital (Hokkaido, Japan) waived the requirement for written informed consent from the patient's family for use of patient's data in this manuscript.

\section{Patient consent to publication}

It was impossible to obtain permission and none of the patient's family would be unlikely to object to publication.

\section{Competing interests}

The authors declare that they have no competing interests.

\section{References}

1. Pardoll DM: The blockade of immune checkpoints in cancer immunotherapy. Nat Rev Cancer 12: 252-264, 2012.

2. Brahmer J, Reckamp KL, Baas P, Crino L, Eberhardt WE, Poddubskaya E, Antonia S, Pluzanski A, Vokes EE, Holgado E, et al: Nivolumab versus docetaxel in advanced squamous-cell non-small-cell lung cancer. N Engl J Med 373: 123-135, 2015.

3. Borghaei H, Paz-Ares L, Horn L, Spigel DR, Steins M, Ready NE, Chow LQ, Vokes EE, Felip E, Holgado E, et al: Nivolumab versus docetaxel in advanced nonsquamous non-small-cell lung cancer. N Engl J Med 373: 1627-1639, 2015.

4. Gettinger S, Rizvi NA, Chow LQ, Borghaei H, Brahmer J, Ready N, Gerber DE, Shepherd FA, Antonia S, Goldman JW, et al: Nivolumab monotherapy for first-line treatment of advanced non-small-cell lung cancer. J Clin Oncol 34: 2980-2987, 2016.

5. Derks JL, Hendriks LE, Buikhuisen WA, Groen HJ, Thunnissen E, van Suylen RJ, Houben R, Damhuis RA, Speel EJ and Dingemans AM: Clinical features of large cell neuroendocrine carcinoma: A population-based overview. Eur Respir J 47: 615-624, 2016.

6. Travis WD, Brambilla E, Burke AP, Marx A and Nicholson AG (eds): WHO classification of tumours of the lung, pleura, thymus and heart. 4th edition. Lyon, Int Agency Res Cancer, 2015 . 
7. Niho S, Kenmotsu H, Sekine I, Ishii G, Ishikawa Y, Noguchi M, Oshita F, Watanabe S, Nakajima R, Tada $H$ and Nagai $K$ : Combination chemotherapy with irinotecan and cisplatin for large-cell neuroendocrine carcinoma of the lung: A multicenter phase II study. J Thorac Oncol 8: 980-984, 2013.

8. Le Treut J, Sault MC, Lena H, Souquet PJ, Vergnenegre A, Le Caer H, Berard H, Boffa S, Monnet I, Damotte D and Chouaid C: Multicentre phase II study of cisplatin-etoposide chemotherapy for advanced large-cell neuroendocrine lung carcinoma: The GFPC 0302 study. Ann Oncol 24: 1548-1552, 2013.

9. Kasahara N, Wakuda K, Omori S, Nakashima K, Ono A, Taira T, Kenmotsu H, Naito T, Murakami H, Mori K, et al: Amrubicin monotherapy may be an effective second-line treatment for patients with large-cell neuroendocrine carcinoma of high-grade non-small-cell neuroendocrine carcinoma. Mol Clin Oncol 6: 718-722, 2017.

10. Derks JL, van Suylen RJ, Thunnissen E, den Bakker MA, Groen HJ, Smit EF, Damhuis RA, van den Broek EC, Speel EM and Dingemans AC; PALGA group: Chemotherapy for pulmonary large cell neuroendocrine carcinomas: Does the regimen matter? Eur Respir J 49: pii: 1601838, 2017.

11. Chen YB, Mu CY and Huang JA: Clinical significance of programmed death-1 ligand-1 expression in patients with non-small cell lung cancer: A 5-year-follow-up study. Tumori 98: 751-755, 2012.

12. Garon EB, Rizvi NA, Hui R, Leighl N, Balmanoukian AS, Eder JP, Patnaik A, Aggarwal C, Gubens M, Horn L, et al: Pembrolizumab for the treatment of non-small-cell lung cancer. N Engl J Med 372: 2018-2028, 2015.

13. Tsuruoka K, Horinouchi H, Goto Y, Kanda S, Fujiwara Y, Nokihara H, Yamamoto N, Asakura K, Nakagawa K, Sakurai H, et al: PD-L1 expression in neuroendocrine tumors of the lung. Lung Cancer 108: 115-120, 2017.

14. Wang VE, Urisman A, Albacker L, Ali S, Miller V, Aggarwal R and Jablons D: Checkpoint inhibitor is active against large cel neuroendocrine carcinoma with high tumor mutation burden. J Immunother Cancer 5: 75, 2017.
15. Mauclet C, Duplaquet F, Pirard L, Rondelet B, Dupont M, Pop-Stanciu C, Vander Borght T, Remmelink M, D'Haene N, Lambin S, et al: Complete tumor response of a locally advanced lung large-cell neuroendocrine carcinoma after palliative thoracic radiotherapy and immunotherapy with nivolumab. Lung Cancer 128: 53-56, 2019.

16. McLaughlin J, Han G, Schalper KA, Carvajal-Hausdorf D, Pelekanou V, Rehman J, Velcheti V, Herbst R, LoRusso P and Rimm DL: Quantitative assessment of the heterogeneity of PD-L1 expression in non-small-cell lung cancer. JAMA Oncol 2: 46-54, 2016.

17. Munari E, Zamboni G, Marconi M, Sommaggio M, Brunelli M, Martignoni G, Netto GJ, Moretta F, Mingari MC, Salgarello M, et al: PD-L1 expression heterogeneity in non-small cell lung cancer: Evaluation of small biopsies reliability. Oncotarget 8: 90123-90131, 2017.

18. Sabari JK, Julian RA, Ni A, Halpenny D, Hellman MD, Drilon AE, Li BT, Poirier JT, Rudin CM and Rekhtman N: Outcomes of advanced pulmonary large cell neuroendocrine carcinoma stratified by RB1 loss, SLFN11 expression, and tumor mutational burden. J Clin Oncol 36 (15 Suppl): e20568, 2018.

19. Grangeon M, Tomasini P, Chaleat S, Jeanson A, Souquet-Bressand M, Khobta N, Bermudez J, Trigui Y, Greillier L, Blanchon $\mathrm{M}$, et al: Association between immune-related adverse events and efficacy of immune checkpoint inhibitors in non-small-cell lung cancer. Clin Lung Cancer 20: 201-207, 2019.

This work is licensed under a Creative Commons Attribution-NonCommercial-NoDerivatives 4.0 International (CC BY-NC-ND 4.0) License. 